Revista Tecné, Episteme y Didaxis: TED. Año 2014, Número Extraordinario. ISSN Impreso: 0121-3814, ISSN web: 2323-0126

Memorias, Sexto Congreso Internacional sobre Formación de Profesores de Ciencias. 08 al 10 de octubre de 2014, Bogotá

\title{
Dispositivos teórico-metodológicos para el diseño, desarrollo y evaluación de estrategias didácticas
}

Pereda-García Sara' ' López-Mota Ángel2, López-Gordillo Mercedes ${ }^{3}$

Categoría 1. Reflexiones y experiencias desde la innovación en el aula

\section{Resumen}

Presentamos y discutimos un conjunto de estrategias didácticas (ED) en forma de tesis, elaboradas por estudiantes de la Maestría en Desarrollo Educativo en la Universidad Pedagógica Nacional. Ello responde a la crisis existente en la enseñanza y aprendizaje de las ciencias en México, por lo que optamos seguir esta línea de investigación para buscar una mejor manera de enseñar y aprender ciencias.

\section{Palabras clave}

Estrategias Didácticas, Modelos, Modelización, Desarrollo Curricular, Formación Continua de Profesores.

\section{Introducción}

En el campo de Educación en Ciencias existe actualmente un creciente interés por las estrategias didácticas; concebidas como herramientas básicas de planificación, para mejorar los procesos de enseñanza y aprendizaje de temas científicos.

La complejidad de este proceso propició una importante línea de investigación que implica el diseño y aplicación de estrategias de enseñanza. Esto ha ocasionado que muchas contribuciones de este campo hagan referencia a las secuencias de enseñanza con objetivos, sustentos y alcances diversos (Méheut \& Psillos, 2004).

\footnotetext{
1 Universidad Pedagógica Nacional: <peredag@yahoo.com>

2 Universidad Pedagógica Nacional: <alopezm@upn.mx>

3 Benemérita Escuela Nacional de Maestros: <mercy_sal@prodigy.net.mx>
} 
Revista Tecné, Episteme y Didaxis: TED. Año 2014, Número Extraordinario. ISSN Impreso: 0121-3814, ISSN web: 2323-0126

Memorias, Sexto Congreso Internacional sobre Formación de Profesores de Ciencias. 08 al 10 de octubre de 2014, Bogotá

Así, se han propuesto para su diseño diferentes marcos teóricos como el cambio conceptual (Strike \& Posner, 1985; Chi Et. Al., 1994; Vosniadou \& loannides, 1998; Duit y Treagust, 2003), y la modelización (Justi, 2006; García y Sanmartí 2006; Adúriz e Izquierdo, 2009). Incluso se ha discutido si la propia elaboración y evaluación de las secuencias de enseñanza no es el objetivo fundamental de investigación de la Didáctica de las Ciencias (Couso, 2011).

Por ello, el programa de maestría de la UPN, línea de Educación en Ciencias, busca contribuir a la formación continua de profesores, involucrando a sus participantes en la realización de proyectos de intervención didáctica.

\section{Desarrollo}

El propósito de estos proyectos de intervención es el de diseñar, aplicar y evaluar una ED para transformar las ideas previas -en el contexto del cambio conceptualy los modelos -en el caso de la modelización- de los estudiantes.

Una característica común de estas Ed, es que se orientan desde una perspectiva constructivista porque ponen al estudiante en el centro de la actividad escolar. Además, proponen actividades didácticas secuenciadas que involucran cuestionarios, actividades experimentales, videos, trabajo colaborativo, lecturas, entre otros; para promover la construcción del conocimiento y dar cuenta de este proceso. 
Revista Tecné, Episteme y Didaxis: TED. Año 2014, Número

Extraordinario. ISSN Impreso: 0121-3814, ISSN web: 2323-0126

Memorias, Sexto Congreso Internacional sobre Formación de

Profesores de Ciencias. 08 al 10 de octubre de 2014, Bogotá

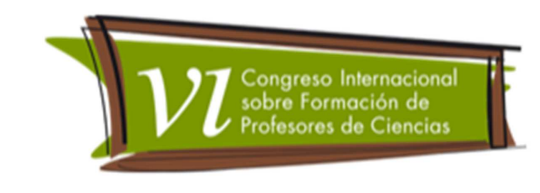

Tabla 1. ED fundamentadas en el Cambio Conceptual, la Modelización y el Modelo Científico Escolar de Arribo (Mcea).

\begin{tabular}{|c|c|c|c|c|c|c|}
\hline & \multirow[b]{2}{*}{ Autor } & \multirow[b]{2}{*}{ Campo de Estudio } & \multirow[b]{2}{*}{ Población } & \multicolumn{3}{|c|}{ Metodología } \\
\hline & & & & $\begin{array}{l}\text { Objetos y formas de } \\
\text { transformación }\end{array}$ & Acciones Estratégicas & Resultados \\
\hline \multirow{2}{*}{ 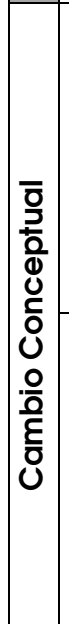 } & $\begin{array}{l}\text { Pereda, S. } \\
\text { (2008) }\end{array}$ & Electrostática & $\begin{array}{l}\text { 2 secundaria } \\
\text { (12-13 años) }\end{array}$ & $\begin{array}{l}\text { Evocar ideas previas. } \\
\text { Confrontar ideas. } \\
\text { Verificar la } \\
\text { transformación de } \\
\text { ideas. }\end{array}$ & $\begin{array}{l}\text { Conflictuar } \\
\text { cognitivamente. } \\
\text { Uso de analogías } \\
\text { Uso y aplicación de } \\
\text { nuevos conceptos. }\end{array}$ & $\begin{array}{l}\text { Alumnos incorporan en sus ideas } \\
\text { fenómenos y conceptos nuevos: } \\
\text { "frotación", "chispas", "toques", } \\
\text { "cargas eléctricas", el relámpago; y } \\
\text { dejaron de confundir éstos con } \\
\text { fenómenos magnéticos. }\end{array}$ \\
\hline & $\begin{array}{l}\text { Reyes, L. G. } \\
\text { (2008) }\end{array}$ & Seres Vivos & $\begin{array}{c}\text { 3 Preescolar } \\
\text { (4-5 años) }\end{array}$ & $\begin{array}{l}\text { Evocar ideas previas y } \\
\text { confrontarlas. } \\
\text { Detectar la } \\
\text { transformación de } \\
\text { ideas. }\end{array}$ & $\begin{array}{l}\text { Generar conflicto. } \\
\text { Usar y aplicar nuevos } \\
\text { conceptos. }\end{array}$ & $\begin{array}{l}\text { Niños logran no poner énfasis en la } \\
\text { posesión de características } \\
\text { antropomorfas en la identificación } \\
\text { de seres vivos y reconocen } \\
\text { características tales como nacer, } \\
\text { crecer, alimentarse, respirar, tener } \\
\text { hijos como propias de los seres vivos. }\end{array}$ \\
\hline $\begin{array}{l}\frac{1}{0} \\
\frac{0}{0} \\
\frac{N}{0} \\
\frac{0}{0} \\
\frac{0}{\Sigma} \\
\frac{0}{2}\end{array}$ & $\begin{array}{l}\text { Moreno, G. } \\
\text { (2010) }\end{array}$ & Fermentación & $\begin{array}{c}1^{\circ} \\
\text { secundaria } \\
\text { (12-13 años) }\end{array}$ & $\begin{array}{l}\text { Identificar sus } \\
\text { concepciones } \\
\text { alternativas } \\
\text { Contrastar modelos - } \\
\text { inferidos de las ideas } \\
\text { previas- e ideas } \\
\text { presentes después de } \\
\text { la modelización. }\end{array}$ & $\begin{array}{l}\text { Reconocer elementos } \\
\text { constitutivos del } \\
\text { modelo, así como } \\
\text { relaciones y } \\
\text { condiciones, mediante } \\
\text { procedimientos } \\
\text { experimentales. }\end{array}$ & $\begin{array}{l}\text { Alumnos consideran al yogurt como } \\
\text { producto de la digestión de los } \\
\text { búlgaros. } \\
\text { Dificultades para explicar este } \\
\text { fenómeno como un proceso } \\
\text { microscópico. }\end{array}$ \\
\hline$\frac{b^{2}}{b^{2}}$ & $\begin{array}{l}\text { López, M. } \\
\text { (2011) }\end{array}$ & $\begin{array}{l}\text { Digestión- } \\
\text { circulación }\end{array}$ & $\begin{array}{l}4^{\circ} \text { primaria } \\
\text { (9-10 años) }\end{array}$ & $\begin{array}{l}\text { Identificar y confrontar } \\
\text { Ideas previas, así como } \\
\text { los nuevos elementos y } \\
\text { relaciones del modelo } \\
\text { construido. }\end{array}$ & $\begin{array}{l}\text { Usar analogías } \\
\text { presentadas en } \\
\text { experimentos. } \\
\text { Promover la } \\
\text { observación, la }\end{array}$ & $\begin{array}{l}\text { Alumnos reconocen la articulación } \\
\text { entre el sistema digestivo y } \\
\text { circulatorio, mediante vellosidades } \\
\text { intestinales y el sistema porta- } \\
\text { hepático, así como el paso de }\end{array}$ \\
\hline
\end{tabular}


Revista Tecné, Episteme y Didaxis: TED. Año 2014, Número Extraordinario. ISSN Impreso: 0121-3814, ISSN web: 2323-0126

Memorias, Sexto Congreso Internacional sobre Formación de Profesores de Ciencias. 08 al 10 de octubre de 2014, Bogotá

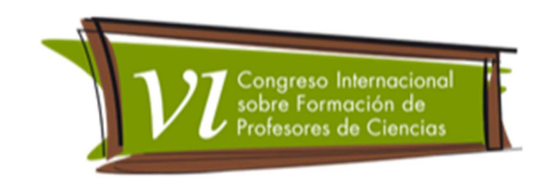

\begin{tabular}{|c|c|c|c|c|c|c|}
\hline & & & & & $\begin{array}{l}\text { construcción de } \\
\text { nuevas ideas y ampliar } \\
\text { modelo inicial. }\end{array}$ & nutrimentos a la sangre. \\
\hline & $\begin{array}{l}\text { Salgado, } \\
\text { G. (2013) }\end{array}$ & $\begin{array}{l}\text { Evolución } \\
\text { biológica }\end{array}$ & $\begin{array}{l}\text { 1 secundaria } \\
\text { (12-13 años) }\end{array}$ & $\begin{array}{l}\text { Evocar concepciones } \\
\text { alternativas. } \\
\text { Evidenciar el modelo } \\
\text { cognitivo intermedio y } \\
\text { el alcanzado al final. }\end{array}$ & $\begin{array}{l}\text { Estructurar nuevos } \\
\text { elementos a su modelo } \\
\text { inicial. } \\
\text { Promover la discusión y } \\
\text { consenso de } \\
\text { elementos y relaciones } \\
\text { para la construcción } \\
\text { de modelos. }\end{array}$ & $\begin{array}{l}\text { Alumnos logran incorporar } \\
\text { elementos: ser vivo, especie y } \\
\text { poblaciones. } \\
\text { Y relaciones: cambios lentos, } \\
\text { variabilidad, sobrevivencia, } \\
\text { recombinación genética, } \\
\text { reproducción, generaciones, } \\
\text { adaptación y mutación. }\end{array}$ \\
\hline 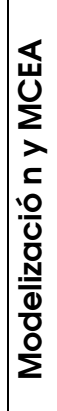 & $\begin{array}{l}\text { Mendoza, } \\
\text { M. N. } \\
\text { (2012) }\end{array}$ & $\begin{array}{l}\text { Movimiento } \\
\text { (Leyes de } \\
\text { Newton) }\end{array}$ & $\begin{array}{l}2^{\circ} \\
\text { Secundaria } \\
\text { (12-13 años) }\end{array}$ & $\begin{array}{l}\text { Contrastar modelo } \\
\text { cognitivo inicial con el } \\
\text { construido al final. } \\
\text { Verificar qué tanto se } \\
\text { acercan al MCEA. }\end{array}$ & $\begin{array}{l}\text { Evocar ideas previas. } \\
\text { Incorporar nuevos } \\
\text { elementos y construir } \\
\text { un nuevo modelo. } \\
\text { Aplicar el modelo } \\
\text { construido en } \\
\text { situaciones distintas a } \\
\text { la inicial. }\end{array}$ & $\begin{array}{l}\text { Alumnos -en equipos- logran el } \\
\text { siguiente modelo: la superficie sobre } \\
\text { la que se mueve un cuerpo es } \\
\text { importante (fricción). Establecen una } \\
\text { relación de proporcionalidad Fuerza- } \\
\text { Aceleración. } \\
\text { No se cubre la relación de que en los } \\
\text { cuerpos en reposo no actúan } \\
\text { fuerzas. }\end{array}$ \\
\hline 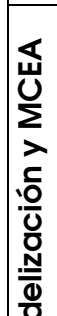 & $\begin{array}{l}\text { García, R. } \\
\text { (2013) }\end{array}$ & $\begin{array}{l}\text { Crecimiento de } \\
\text { las Plantas } \\
\text { (Transformación } \\
\text { de la energía) }\end{array}$ & $\begin{array}{c}1^{\circ} \\
\text { Secundaria } \\
\text { (12-13 años) }\end{array}$ & $\begin{array}{l}\text { Extraer elementos del } \\
\text { modelo inicial e } \\
\text { intermedio. } \\
\text { Justificar y argumentar } \\
\text { explicaciones. } \\
\text { Verificar qué tanto se } \\
\text { acercan al MCEA. }\end{array}$ & $\begin{array}{l}\text { Explorar y confrontar } \\
\text { sus ideas. } \\
\text { Identificar e incorporar } \\
\text { nuevos elementos y } \\
\text { relaciones en sus } \\
\text { modelos. }\end{array}$ & $\begin{array}{l}\text { Alumnos logran el siguiente modelo: } \\
\text { Si la planta se alimenta, crece. } \\
\text { Raíces absorben agua y minerales } \\
\text { que llegan a toda la planta. Éstos y el } \\
\mathrm{CO}_{2} \text { son necesarios para elaborar } \\
\text { alimento. La luz se relaciona con el } \\
\text { color de la planta. }\end{array}$ \\
\hline$\stackrel{8}{\Sigma}$ & $\begin{array}{l}\text { Martínez, } \\
\text { C. (2013) }\end{array}$ & $\begin{array}{l}\text { Nutrición de las } \\
\text { Plantas Verdes }\end{array}$ & $\begin{array}{l}\text { 3 Primaria (8- } \\
9 \text { años) }\end{array}$ & $\begin{array}{l}\text { Identificar elementos y } \\
\text { relaciones en el }\end{array}$ & $\begin{array}{l}\text { Explorar ideas previas. } \\
\text { Reconceptualizar }\end{array}$ & $\begin{array}{l}\text { Niños logran el siguiente modelo: las } \\
\text { plantas verdes son seres autótrofos, }\end{array}$ \\
\hline
\end{tabular}


Revista Tecné, Episteme y Didaxis: TED. Año 2014, Número Extraordinario. ISSN Impreso: 0121-3814, ISSN web: 2323-0126 Memorias, Sexto Congreso Internacional sobre Formación de Profesores de Ciencias. 08 al 10 de octubre de 2014, Bogotá

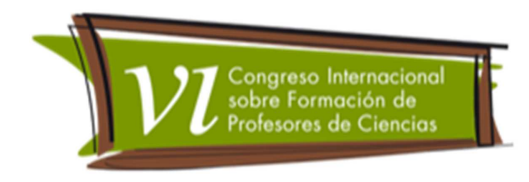

\begin{tabular}{|c|c|c|c|c|c|}
\hline & (Fotosíntesis) & & $\begin{array}{l}\text { modelo cognitivo } \\
\text { inicial. } \\
\text { Argumentar } \\
\text { explicaciones. } \\
\text { Verificar qué tanto se } \\
\text { acercan al MCEA. }\end{array}$ & $\begin{array}{l}\text { nuevos elementos y } \\
\text { relaciones. } \\
\text { Proponer situaciones } \\
\text { distintas para usar el } \\
\text { modelo construido. }\end{array}$ & $\begin{array}{l}\text { que necesitan } \mathrm{H}_{2} \mathrm{O}, \mathrm{CO}_{2} \text { y luz solar. } \\
\text { El tallo almacena alimento. } \\
\text { Raíces absorben agua del suelo. }\end{array}$ \\
\hline $\begin{array}{l}\text { Sánchez, } \\
\text { M. G. } \\
\text { (2013) }\end{array}$ & $\begin{array}{l}\text { Sistema } \\
\text { Locomotor } \\
\text { humano }\end{array}$ & $\begin{array}{c}\text { 3o Primaria (8- } \\
9 \text { años) }\end{array}$ & $\begin{array}{l}\text { Identificar elementos y } \\
\text { relaciones en el } \\
\text { modelo cognitivo } \\
\text { inicial. } \\
\text { Verificar qué tanto se } \\
\text { acercan al MCEA. }\end{array}$ & $\begin{array}{l}\text { Introducir elementos y } \\
\text { condiciones del MCEA } \\
\text { ausentes en el Modelo } \\
\text { inicial. Contrastar } \\
\text { ideas, Aplicar el } \\
\text { modelo alcanzado a } \\
\text { otro contexto. }\end{array}$ & $\begin{array}{l}\text { Alumnos relacionan cerebro, nervios, } \\
\text { huesos, músculos, articulaciones y } \\
\text { tendones; y entidades del sistema } \\
\text { locomotor con extremidades. } \\
\text { Dificultad al incorporar los estímulos } \\
\text { externos al modelo y relacionarlos } \\
\text { con los órganos de los sentidos y del } \\
\text { movimiento. }\end{array}$ \\
\hline
\end{tabular}


Revista Tecné, Episteme y Didaxis: TED. Año 2014, Número Extraordinario. ISSN Impreso: 0121-3814, ISSN web: 2323-0126

Memorias, Sexto Congreso Internacional sobre Formación de Profesores de Ciencias. 08 al 10 de octubre de 2014, Bogotá

\section{Análisis y conclusiones}

Los trabajos exploran las ideas previas con propósitos didácticos diferenciados, según los sustentos teóricos utilizados. Unos pretenden transformar las ideas de los estudiantes, teniendo como referente el currículum. Otros buscan transformar los modelos estudiantiles -habiendo homogeneizado información en forma de modelos-, orientados por un dispositivo didáctico llamado Modelo Científico Escolar de Arribo (López y Rodríguez, 2013), el cual presupone un modelo hipotético a ser alcanzado por los estudiantes y puesto a prueba en la práctica docente.

La incorporación de la modelización como dispositivo teórico e instrumento de desarrollo didáctico ha sido paulatina e instrumentada con diferentes niveles de profundidad y logros más o menos importantes. Además, lleva implícita una transición en la forma de concebir los logros didácticos -el aprendizaje o la construcción de conocimientos-, primeramente entendidos como la suplantación de una idea por otra (cambio conceptual), y después como un proceso continuo -que va desde el conocimiento intuitivo hasta el científico- enfocado a la construcción de modelos científicos escolares.

Parece no existir todavía una manera de sustentar una determinada forma de modelizar. Creemos que el Mcea es un referente adecuado para diseñar y validar Ed en sí mismas -por lo que pueden lograr frente a una clara hipótesis- que exige homogeneizar información en términos de modelos y explicitar sus constituyentes y condiciones. Además representa una hipótesis directriz que guía la construcción de modelos y no de conceptos aislados en condiciones de clase.

En general, la evaluación de las Ed permite cuestionar la formulación especulativa de aprendizajes esperados en el currículo oficial y caracterizar la relativa dificultad de un determinado propósito de enseñanza.

\section{Referencias}

Adúriz-Bravo, A. e Izquierdo Aymerich, M. (febrero, 2009). Un modelo de modelo científico para la enseñanza de las ciencias naturales. Revista Electrónica de Investigación en Educación en Ciencias. 4(1) pág. 40-49. 
Revista Tecné, Episteme y Didaxis: TED. Año 2014, Número Extraordinario. ISSN Impreso: 0121-3814, ISSN web: 2323-0126

Memorias, Sexto Congreso Internacional sobre Formación de Profesores de Ciencias. 08 al 10 de octubre de 2014, Bogotá

Chi, M., Slotta, J. \& Leeuw, N. (1994). From things to processes: a theory of conceptual change for learning science concepts. Learning and Instruction, pág. 4, 27-43.

Couso, D. (2011). Las secuencias didácticas en la enseñanza y el aprendizaje de las ciencias: modelos para su diseño y validación. En A. Caamaño (Coord.) Didáctica de la Física y la Química. (pág. 57-83). España: Graco.

Duit, R., \& Treagust, D. (2003). Conceptual change: a powerful framework for improving science teaching and learning. International Journal of Science Education, pág. 25, 671-688.

García, R. y Flores, M. (2013). Una estrategia Didáctica en secundaria utilizando la modelización. Entre maestros, 13 (45) pág. 6-11.

García, P. y Sanmartí, N. (2006). La modelización: una propuesta para repensar la ciencia que enseñamos. En M. Quintanilla y A. Adúriz-Bravo, Enseñar ciencias en el nuevo milenio. Retos y propuestas. (pág. 279-295). Santiago de Chile: Universidad Católica de Chile.

Justi, R. (2006). La enseñanza de ciencias basada en la elaboración de modelos. Enseñanza de las Ciencias, 24(2), pág. 173-184.

López, M. (2011). Estrategia didáctica para promover en alumnos de educación primaria la construcción de un modelo sobre digestión-circulación de nutrimentos en el cuerpo humano, más próximo al modelo científico escolar (Tesis de maestría). Recuperada de Biblioteca Gregorio Torres Quintero (Adquisición No. 125885)

López-Mota, A. y Rodríguez-Pineda, D. P. (2013). Anclaje de los modelos y la modelización científica en estrategias didácticas. Enseñanza de las ciencias, Núm. Extra, 2008-2013.

Martínez, C. (2013). Estrategia didáctica para promover la construcción del modelo de nutrición de las plantas verdes en la escuela primaria. (Tesis de maestría inédita) Universidad Pedagógica Nacional, México, D. F.

Méheut, M. \& Psillos, D. (2004). Teaching-learning sequences: aims and Tools for science education research. International Journal of Science Education, 26(5), pág. 515-535. 
Revista Tecné, Episteme y Didaxis: TED. Año 2014, Número Extraordinario. ISSN Impreso: 0121-3814, ISSN web: 2323-0126

Memorias, Sexto Congreso Internacional sobre Formación de Profesores de Ciencias. 08 al 10 de octubre de 2014, Bogotá

Mendoza, M. N. (2012) Estrategia didáctica para la construcción de un modelo científico escolar sobre movimiento en alumnos de secundaria. (Tesis de maestría). Recuperada de Biblioteca Gregorio Torres Quintero (Adquisición No. 146408)

Moreno, G. (2011). Construcción de modelos escolares, en un grupo de primero de secundaria, acerca de la fermentación. (Tesis de maestría). Recuperada de Biblioteca Gregorio Torres Quintero (Adquisición No. 124308)

Pereda, S. (2008) Diseño de una estrategia didáctica para propiciar el cambio conceptual sobre electrostática en alumnos de secundaria. (Tesis de maestría). Recuperada de Biblioteca Gregorio Torres Quintero (Adquisición No. 263376)

Reyes, L. G. (2008) Estrategia Didáctica para transformar las concepciones de los niños preescolares sobre seres vivos. (Tesis de maestría). Recuperada de Biblioteca Gregorio Torres Quintero (Adquisición No. 263421)

Salgado, G. I. (2012) Construcción de modelos escolares sobre evolución biológica: una estrategia sustentada en la modelización. (Tesis de maestría). Recuperada de Biblioteca Gregorio Torres Quintero (Adquisición No. 143737)

Sánchez, M. G. (2013) Estrategia didáctica fundamentada en la modelización para la construcción escolar de un modelo científico sobre el movimiento del cuerpo humano. (Tesis de maestría inédita) Universidad Pedagógica Nacional, México, D. F.

Strike, K. \& Posner, G. (1985). Conceptual Change View of Learning and Understanding. En Pines \& West Cognitive Structure and Conceptual Change. Academic Press. pág. 211-232.

Voniadou, S. \& loannides, C. (1998). From conceptual development to science education: A psichological of point of view. International Journal of Science Education 20(10), pág. 1213-1230. 